\title{
ASPECTOS GEOQUIMICOS DAS AGUAS SUBTERRÂNEAS DA REGIÃO DE BERTIOGA, ESTADO DE SÃO PAULO, BRASIL
}

\author{
MÁRIA SZIKSZAY*, ALDO DA CUNHA REBOUÇAS* e NELSON ELLERT*
}

\begin{abstract}
The objective of this work was the characterization of conditions of ground-water wells in the above mentioned area. Methodology included an extensive sampling to obtain fundamental hydrogeological data, technical informations relating to well drilling and the relative position of wells vs cesspool. Geophysical prospecting (by electroresistivity methods) allowed us to determine the qualitv of the aquifers and the hydrogeological properties of the substratum. Most of the data were obtained by analysis (physicochemical and bacteriological) in situ, with the HACH Water Analysis Kit. Various clegrees of potability were found, mainly on account of the concentration ranges of $\mathrm{Fe}, \mathrm{NH}_{4}, \mathrm{NO}_{2}$, and presence of coliform bacteria. The geochemical interpretation showed three types of water. The study of exchangeable bases revealed that there is a relationship between the chemical composition of waters and the lithology, and also the conditions of circulation of these waters within the rocks. Fluctuation of the concentrations of $\mathrm{Fe}$ and $\mathrm{Cl}$ are controlled by the distance from the beach, on the other hand the TDS, $\mathrm{NH}_{4}$ and $\mathrm{NO}_{3}$, by conditions of circulation.
\end{abstract}

INTRODUÇÃo A área de estudo cobre uma superfície de aproximadamente $80 \mathrm{~km}^{2}$, $20 \mathrm{~km}$ de comprimento por $4 \mathrm{~km}$ de largura média. Este domínio costeiro encontra-se ainda muito irregularmente habitado e com predominância de veranistas em relação à população permanente.

Um aquífero livre é utilizado através de captação domiciliar (poços encravados e poços rasos) e constitui o principal manancial ora em uso. Contudo, poço e fossa caminham paripassu. Face à pequena profundidade do nível das águas subterrâneas e o caráter poroso do solo, os riscos de contaminação do manancial são muito grandes.

O problema consistiu, portanto, da determinação das condiçz̃es de exploração com vista ao abastecimento dos núcleos populacionais em desenvolvimento na área.

Este estudo foi realizado em cumprimento ao contrato celebrado entre o Instituto de Geociências da USP e a Superintendência da Baixada Santista.

TRABALHOS REALIZADOS A metodologia empregada visou à obtenção de dados hidrogeologicos, geofísicos e hidroquímicos (Fig. 1).

O estudo hidrogeológico envolveu o cadastramento dos pontos de água (poços encravados e poços rasos), a determinação da posição relativa poço $\mathrm{x}$ fossa, a profundidade de captação e a profundidade do nível d'água.

A pesquisa geofisica objetivou a obtenção de informações sobre espessuras, litologia dos materiais aquíferos, posição da interface ao longo da costa e topografia do substrato rochoso.

O estudo hidrogeoquímico teve por finalidade determinar a qualidade da água, sob o aspecto de potabilidade (química e bacteriológica), como também um estudo mais detalhado para classificar as águas e relacioná-las com a litologia.

CONDIÇOES HIDROGEOLÓGICAS A planície costeira investigada é geologicamente constituída por sedimentos flúvio-marinhos quaternários, cobrindo um substrato rochoso. Este é composto de rochas do precambriano (granitos, gnaisses, mica xistos). Os

*Instituto de Geociências, Universidade de Sào Paulo, caixa postal 20899, São Paulo, SP 


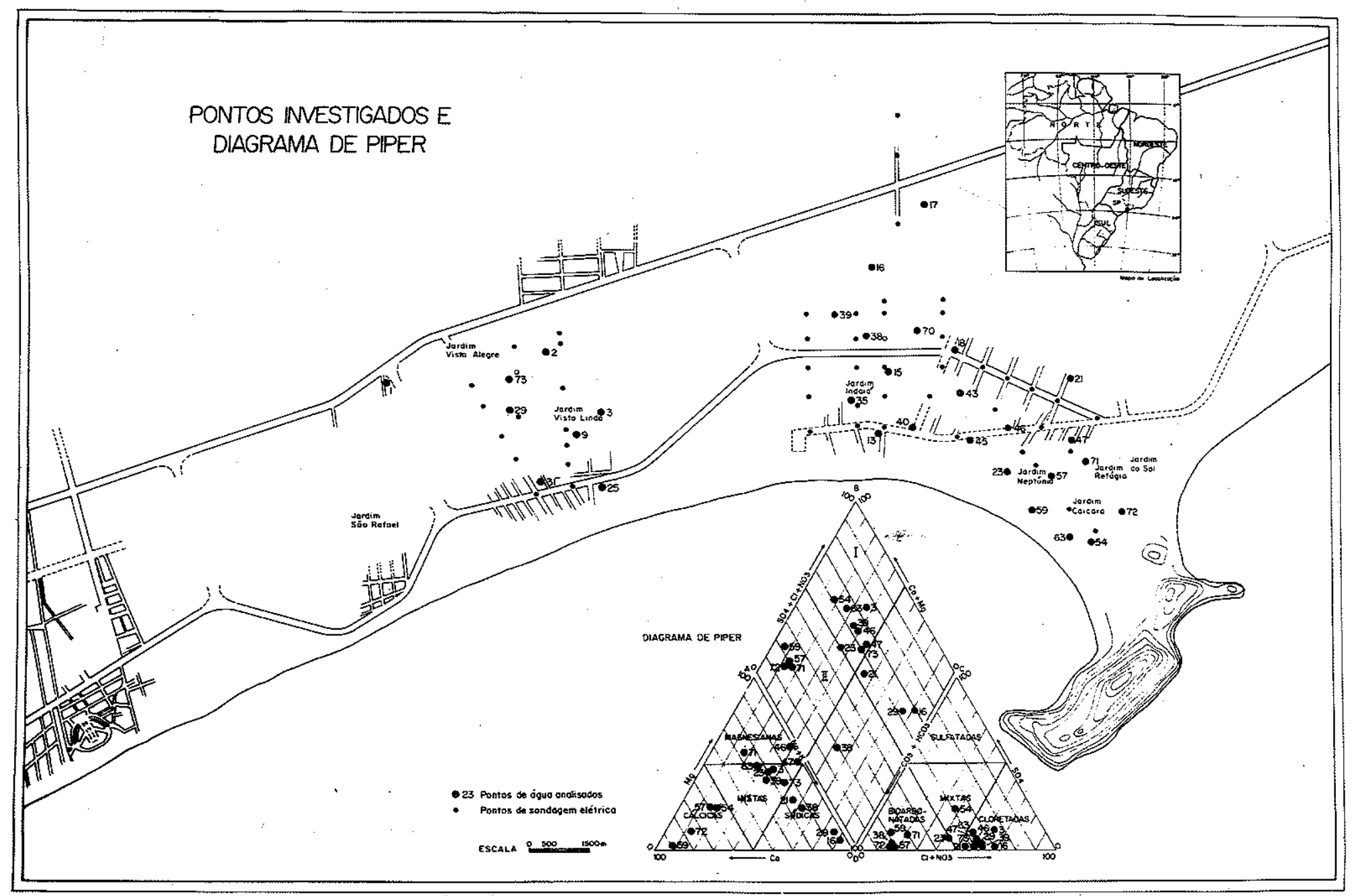

Figura I - Mapa dos pontos investigados e diagrama de Piper 
sedimentos são predominantemente arenosos, finos a médios, intercalados, às vezes, com argilas orgânicas.

As elevações mais importantes do paleorrelevo assoreado constituem promontórios e ilhas que se realçam em alguns pontos da região.

A área pertence a uma das zonas mais chuvosas do Estado de São Paulo (umidade relativa média superior a $80 \%$ e pluviometria média de $3950 \mathrm{~mm} / \mathrm{ano}$ ).

A distribuição anual revela a existência de dois trimestres especialmente chuvosos (fevereiro, março e abril, e agosto, setembro e outubro) separados por dois outros (maio, junho e julho, e novembro, dezembro e janeiro), cujas pluviometrias são relativamente menos elevadas (fonte: Bol. Pluviométrico, DAEE).

As medidas de nível revelam a presença de um aquífero cujo nível estático se encontra a uma profundidade variável entre 1 e $2 \mathrm{~m}$.

A feição topográfica do terreno condiciona a existência de um interflúvio superficial situado a uma distância de 200 a $250 \mathrm{~m}$ da costa.

A partir dessa linha, os fluxos se dirigem seja rumo ao mar, seja ao sistema de drenagem interior.

DADOS GEOFISICOS O conjunto de diagramas de 55 sondagens elétricas realizadas revelam o caráter geoelétrico do recobrimento sedimentar que repousa sobre um horizonte infinitamente resistente, isto é, o substrato cristalino.

Os diagramas das sondagens elétricas colocam em evidência a presença de:

-um conjunto resistente, cujos valores atingem até $2000 \mathrm{ohm} \cdot \mathrm{m}$, que corresponde à parte dos depósitos saturados de água doce;

-um horizonte condutor, com resistividade inferior a $8 \mathrm{ohm} \cdot \mathrm{m}$, indicando a presença de água salgada;

-um substrato infinitamente resistente (o embasamento cristalino), cuja profundidade variou de 60 a $120 \mathrm{~m}$.

Os dois setores onde o substrato é particularmente profundo correspondem certamente a paleovales. Com efeito, observando-se a posição e direção destes, constata-se que os mesmos se encontram no alinhamento dos rios que descem encaixados nos contrafortes da Serra do Mar, a W da área pesquisada. Estes correspondem, grosso modo, às zonas onde o substrato cristalino é mais profundo e com características hidrogeologicas relativamente melhores.

GONDIÇOESS ATUAIS DE EXPLORAÇÃO No momento, as águas subterrâneas são exploradas através de cacimbas rasas de alvenaria ou anéis de concreto e de poços encravados. As profundidades mais freqüentes das cacimbas são de 3 a $4 \mathrm{~m}$. Esta forma de captação é, sobretudo, predominante na faixa mais litorânea até cerca de $250 \mathrm{~m}$ da costa. Os poços encravados atingem uma profundidade média de $12 \mathrm{~m}$ e predominam na faixa mais interiorana. De maneira geral, as captações guardam uma distância média de $15 \mathrm{~m}$ das fossas sanitárias, quando consideradas no terreno do mesmo proprietário. Em relação à propriedade vizinha, esta distância é freqüentemente reduzida a alguns metros.

DADOS HIDROQUÍMICOS As análises foram realizadas por método titulométrico ou pelo aparelho portátil (espectrofotômetro) HACH Water Analysis Kit. Foram feitas as seguintes medidas fisicas: temperatura da água, temperatura do ar, condutividade e, ainda $\mathrm{pH}$. Por métodos titulométricos de campo: $\mathrm{O}_{2}, \mathrm{CO}_{2}, \mathrm{HCO}_{3}, \mathrm{Cl} \mathrm{e}$, às vezes, $\mathrm{Ca} \mathrm{e}$ 
$\mathrm{Mg}$, indrretamente. Com o aparelho HACH Water Analysis Kit, as seguintes determinações foram realizadas no campo: $\mathrm{NH}_{4}, \mathrm{NO}_{2}, \mathrm{NO}_{3}, \mathrm{Fe}$ e $\mathrm{SO}_{4}$. No laboratório, $\mathrm{Ca}$, $\mathrm{Mg}, \mathrm{Na}$ e $\mathrm{K}$. Algumas determinações de Ca e $\mathrm{Mg}$ foram feitas, para controle, no laboratório pelo método de absorção atômica.

A verificação da presença de bactérias colitormes foi feita, no local, com aparelho Colicount.

Após a efetuação das análises, foi feito o equilíbrio iônico para verificação da validade das análises. Somente foram utilizadas as análises cujo erro revelou-se inferior a $\pm 12 \%$.

Os dados das análises são apresentados na Tabela $\mathrm{I}$.

Ao longo de sua trajetória, as águas subterrâneas entram em contato com diferentes substâncias. Em conseqüência, verifica-se uma troca de íons, cujo índice (i.e.b.) foi avaliado

Tabela I - Resultados das anáuises químicas das águas suiuterrâneas de Bertioga, Estado de. São Paulo. Dados: $\mathrm{mg} / \mathrm{l}$. Analista: M. Szikszay

\begin{tabular}{|c|c|c|c|c|c|c|c|c|c|c|c|c|c|c|c|c|c|c|c|}
\hline $\begin{array}{l}\text { Pofo } \\
\mathrm{N}^{\circ}\end{array}$ & $\begin{array}{c}\text { Data da } \\
\text { coleta }\end{array}$ & $\begin{array}{l}\mathrm{T} \text { da } \\
\text { aggua } \\
{ }^{\circ} \mathrm{C}\end{array}$ & $\begin{array}{c}T \text { do } \\
\text { ar } \\
{ }^{\circ} \mathrm{C}\end{array}$ & $\begin{array}{l}\text { Cond. } \\
\text { मmtho/ } \\
\mathrm{cm}\end{array}$ & $\mathrm{pH}$ & STD & $\mathrm{CO}_{2}$ & $\mathrm{O}_{2}$ & $\mathrm{Ca}$ & Mg & $\mathrm{Na}+\mathrm{K}$ & $\mathrm{Fo}$ & $\mathrm{HCO}_{3}$ & $\mathrm{Cl}$ & $\mathrm{SO}_{4}$ & $\mathrm{NH}_{4}$ & $\mathrm{NO}_{2}$ & $\mathrm{NO}_{3}$ & $\begin{array}{l}\text { Bact. coliformes } \\
/ 100 \mathrm{ml}\end{array}$ \\
\hline 1 & $18 / 4 / 75$ & 22 & 19 & 210 & 6 & 180 & & 20 & & & & 0,35 & & 65 & & 3,0 & - & - & \\
\hline 29 & " " & 22 & 24 & 78 & 6 & 70 & 108 & $1 s$ & 0,5 & 0,9 & 13,8 & 1,2 & 20 & 10 & - & 2,45 & 0,05 & 8,8 & bact. não collf. \\
\hline 2 & $"$ & 22 & 25 & 63 & 5 & 57 & 88 & 17 & & & & 1,18 & & 20 & & 0,5 & 0,05 & 6,16 & $“$ \\
\hline $9 \mathrm{~A}$ & $"$ & 23 & 24 & 67 & 5 & 60 & 200 & 21 & & & & 1,08 & & 20 & & 2,45 & 0,08 & 20,68 & 100 \\
\hline 25 & “ & 24 & 24 & 200 & 6 & 162 & 88 & 5 & & & & 0,29 & & 30 & & - & 0,06 & 13,2 & 2200 \\
\hline 31 & $"$ & 23 & 24 & 420 & 6 & 330 & 100 & 7 & & & & 0,18 & & 55 & & - & 0,5 & 19,8 & bact, ndo colif. \\
\hline 17 & $19 / 4 / 75$ & 23 & 22 & 90 & 5 & 78 & 104 & 15 & & & & 1,8 & & 10 & & 0,83 & 0,06 & 7,92 & " $"$ " \\
\hline 16 & " & 22 & 25 & 55 & 5 & 50 & 56 & 30 & 0,5 & 0,7 & 12,1 & 1,0 & 20 & 15 & - & 1,0 & 0,06 & 12,32 & - \\
\hline 38 & $"$ & 24 & 27 & 380 & 6 & 300 & 52 & 17 & 4,0 & 5,0 & 25,8 & 0,2 & 210 & 20 & - & - & 0,07 & 9,68 & bact, nåo colti. \\
\hline 15 & $"$ & 22 & 27 & 158 & 6 & 135 & 120 & 23 & & & & 1,4 & & 15 & & 0.7 & - & 3,0 & \\
\hline 40 & " & 24 & 26 & 220 & 6 & 180 & 16 & 8 & & & & 0,2 & & 30 & & 0,21 & 0,14 & 18,48 & 600 \\
\hline 13 & $"$ & $2 s$ & 26 & 230 & 6 & 180 & 84 & 11 & & & & 1,4 & & 30 & & 0,12 & 0,08 & 7,9 & \\
\hline 35 & $"$ & 25 & 25 & 320 & 6 & 245 & 160 & 6 & & & & 0,9 & & 15 & & 0,87 & 0,04 & 8,3 & \\
\hline 18 & $20 / 4 / 75$ & 23 & 20 & 360 & 5,7 & 290 & 100 & 16 & & & & 0,5 & & 15 & & - & 0,08 & 12,76 & bact. não colif. \\
\hline 43 & $"$ & 22 & 24 & 650 & 5.9 & 440 & 100 & 20 & & & & 0,4 & & 90 & & 0,46 & 0,06 & 11,0 & \\
\hline 45 & $"$ & 24 & 25 & 200 & 5,3 & 162 & 100 & 5 & & & & 0,1 & & 20 & - & - & 0,09 & 13,2 & bact. nuto coltif. \\
\hline 70 & $9 / 5 / 75$ & 22 & 19 & 73 & 6.8 & 66 & 88 & 15 & & & & 1.2 & & 15 & & 0.77 & $0.0 \%$ & 3.92 & 1200 \\
\hline 23 & $"$ & 22 & 23 & 120 & 6.5 & 105 & 96 & 18 & 8,0 & 10,4 & 16,2 & 0,9 & so & 25. & 6 & - & 0,03 & 1,0 & \\
\hline 21 & $"$ & 22 & 25 & 103 & 5,3 & 92 & 68 & 41 & 4,0 & 5,0 & 16,2 . & 1,8 & 45 & 25 & - & 1,1 & - & 6,6 & , \\
\hline 71 & $"$ & 22 & 26. & 580 & 6,2 & 480 & 100 & 23 & 36,0 & 48,5 & 25,5 & 0,9 & 250 & 40 & 24 & 0,9 & 0,14 & 8,8 & \\
\hline 72 & $"$ & 24 & 24 & 430 & 6,2 & 330 & 64 & & 68,0 & 5,7 & 12,5 & 1,18 & 210 & 20 & 3 & 2,3 & 0,03 & 0,8 & 900 \\
\hline 54 & $"$ & 22 & 25 & 470 & 5,7 & 380 & 100 & 7 & 56.0 & 14,2 & 22,6 & 0,08 & 90 & 35 & 44 & 0,06 & 0,06 & 28,6 & - \\
\hline 63 & “ & 24 & 25 & 400 & 5,3 & 320 & 100 & & 16,0 & 20,0 & 22,6 & 0,05 & 40 & 35 & 13 & 0,1 & 0,1 & 48,4 & \\
\hline 59 & " & 23 & 24 & 540 & 6,2 & 430 & 100 & & 100,0 & - & 12,5 & 0,07 & 250 & 20 & 20 & 0,2 & 0,6 & 8,8 & - \\
\hline 39 & $"$ & 22 & 23 & 73 & 5 & 66 & 100 & 5 & 6,0 & 8,5 & 16,2 & 0,9 & 30 & 25 & - & 1,2 & 0,1 & 6,6 & \\
\hline 73 & $10 / 5 / 75$ & 22 & 20 & 93 & 5 & 84 & 100 & 7 & 4,0 & 5,0 & 12,5 & 1,9 & 30 & 20 & - & 1,4 & 0,01 & 5,28 & \\
\hline 3 & “ & 22 & 21 & $65^{\circ}$ & 5 & 58 & 100 & 17 & 7,0 & 10,0 & 15,2 & 0,7 & 30 & 25 & - & 1,1 & 0,01 & 6,6 & \\
\hline 47 & $"$ & 23 & 24 & 156 & 5 & 125 & 160 & 8 & - & 10,0 & 16,2 & 2,0 & 40 & 25 & 3 & 1,5 & 0,01 & 14,0 & 2000 \\
\hline 46 & $"$ & 22 & 23 & 116 & 5,3 & 105 & 100 & 5 & - & 14,0 & 16,2 & 2,0 & 40 & 25 & 3 & 1,4 & - & 14,0 & - \\
\hline 57 & $"$ & 21 & 26 & 400 & 5,9 & 330 & 72 & 8 & 40,0 & 10,0 & 12,5 & 0,25 & 200 & 20 & 2 & 0,1 & 0,03 & 7,9 & 400 \\
\hline
\end{tabular}


pela fórmula seguinte:

$$
\text { i.e.b. }=\frac{r \mathrm{Cl}-r(\mathrm{Na}+\mathrm{K})}{r \mathrm{Cl}}
$$

Os valores obtidos são apresentados na Tab. II.

Tabela II - Valores de índice de trocá de bases

\begin{tabular}{|c|c|}
\hline Pogo No & l. e. b. \\
\hline 73 & $+0,03$ \\
\hline 59 & $+0,03$ \\
\hline 63 & $+0,01$ \\
\hline 54 & $+0,01$ \\
\hline 72 & $+0,03$ \\
\hline 71 & $+0,01$ \\
\hline 57 & $+0,03$ \\
\hline 38 & $-0,74$ \\
\hline 16 & $-0,16$ \\
\hline 29 & $-0,96$ \\
\hline 47 & 0 \\
\hline 3 & 0 \\
\hline 39 & 0 \\
\hline 21 & 0 \\
\hline 23 & 0 \\
\hline 46 & 0 \\
\hline
\end{tabular}

ESTLDO GEOQUÍMICO DAS ÁGUAS Observando a Fig. 1, verifica-se que os índices de troca de bases positivos pertencem a poços restritos a um setor da área. Este setor corresponde a uma como que restinga que liga a planície costeira ao promontórin de rochas cristalinas. Esses poços apresentam ainda os teores de sólidos totais dissolvidos, relativamente, os mais elevados. As águas desse grupo são classificadas como bicarbonato-calco-magnesianas. A presença desse tipo hidroquímico indica maior abundância de cálcio e magnésio nos sedimentos.

Os poços com índice de troca de bases negativos encontram-se nos setores mais afastados da praia. Essas águas são classificadas como bicarbonatadas sódicas (N. $\left.{ }^{\circ} 38\right)$ e clorossulfatadas sódicas (N.\$s 29 e 16), o que indicaria a presença de fácies mais argilosos.

$\mathrm{E}$, finalmente, os poços com índice de troca de bases zero, significando águas cujas trocas de bases são completas ou atingiram equilíbrio. distintos.

Os diferentes tipos de água (diagrama de Piper, Fig. 1) correspondem a três grupos

Grupo I - clorossulfato calco-magnesianas

Grupo II - bicarbonatadas cálcicas

Grupo III - cloretadas ě/ou bicarbonatadas sódicas

O grupo predominante é o clorossulfatado, revelando o caráter dos sedimentos ricos em cloretos e sulfatos que provêm direta ou indiretamente do mar. 
Águas bicarbonatadas encontram-se predominantemente em aquíferos superficiais, como é o caso estudado, mas estão aqui representadas em número reduzido $(59,57,72,71$ e 38) devido à forte influência dos componentes cloretados e sulfatados.

O terceiro grupo $(29,16$ e 38$)$, que poderia ser classificado como cloretadas e/ou bicarbonatadas sódicas, vem corroborar a ação dominante do mar através dos aerossóis, contribuição biodetrítica e outras tormas de intluência.

A distribuição das concentrações de sóliclos totais dissolvidos (Fig. 2) mostra um correlacionamento com a espessura aquífera. Onde o aquífero é mais espesso, a concentração dos sólidos totais dissolvidos é menor; onde o aquífero é menos espesso, tem-se uma maior concentração de sólidos totais dissolvidos. Isso evidencia a influência das melhores condições de circulação no primeiro caso em relação ao segundo, isto é, dos paleovales relativamente aos setores realçados do substrato hidrogeológico. Enquanto aqueles são caminhos preferenciais para os fluxos subterrâneos, estes podem vir a funcionar como barreiras, engendrando a estágnação c conseqüente aumento dos teores salinos. A distribuição dos diferentes elementos analisados obedece praticamente ao mesmo padrão, corroborando, assim, a grande influência das condições de circulação na caracterização dos tipos de águas subterrâneas da área.

Os valores de $\mathrm{pH}$ da água, situados entre 5 e 6,8, relacionam-se com a grande quantidade de matéria orgânica no solo. Estes valores estão, em $98 \%$ dos casos, ligeiramente em desacordo com as normas de potabilidade.

Sobre $50 \%$ das amostras analisadas, foram encontradas bactérias coliformes; denunciando a presença de fossas que estão em contato direto com a água subterrânea. De fato, foi verificada a presença dessas bactérias em poços situados nos setores mais densamente habitados.

Todas essas águas estão fora do limite de potabilidade do ponto de vista bacteriológico.

ASPECTOS DA POTABILIDADE Adotando-se os padrões de potabilidade definidos pela Organização Mundial da Saúde (OMS), verifica-se que, em termos químicos, as águas não se prestam ao consumo humano em seu estado natural (Fig. 3).

Com efeito, os teores em ferro ultrapassam o limite máximo preconizado $(1 \mathrm{mg} / \mathrm{l})$ em $40 \%$ das amostras.

Os valores de amônia, nitritos e nitratos denunciam a presença de matéria orgânica em decomposição. O ciclo está aqui bem representado pela amônia que, sendo a primeira fase da decomposição das proteínas, se encontra em concentrações mais elevadas, muito além dos permitidos para uma água potável ( $\mathrm{em}{ }^{5} 52 \%$ das amostras). O segundo no ciclo é o nitrito, que também está acima dos valores permitidos. $\mathrm{E}$, por último, os nitratos que, sendo a fase final ou mais estável da decomposição das proteínas vegetais ou animais, se encontra com concentrações mais baixas, já dentro dos limites para uma água potável. Dentre as amostras analisadas, apenas 3\% ultrapassam o limite admitido.

As obras de captação das águas subterrâneas devem satistazer a certos requisitos técnicos. É indispensável que se faça uma distinção entre um poço construído e um poço furado.

As águas subterrâneas da área não se prestam, em seu estado natural, ao consumo humano. Temos, com efeito, precárias qualidades organolépticas, ligadas fundamentalmente ao odor e à cor, no domínio de vegetação abundante, e risco de contaminação sanitária nas áreas densamente povoadas.

Ocorre porém que, se medidas corretivas e/ou preventivas forem adotadas, o manancial subterrâneo poderá alimentar um sistema de distribuição provisório.

Com efeito, o odor e a cor, por exemplo, poderão ser eliminados por um simples pro- 


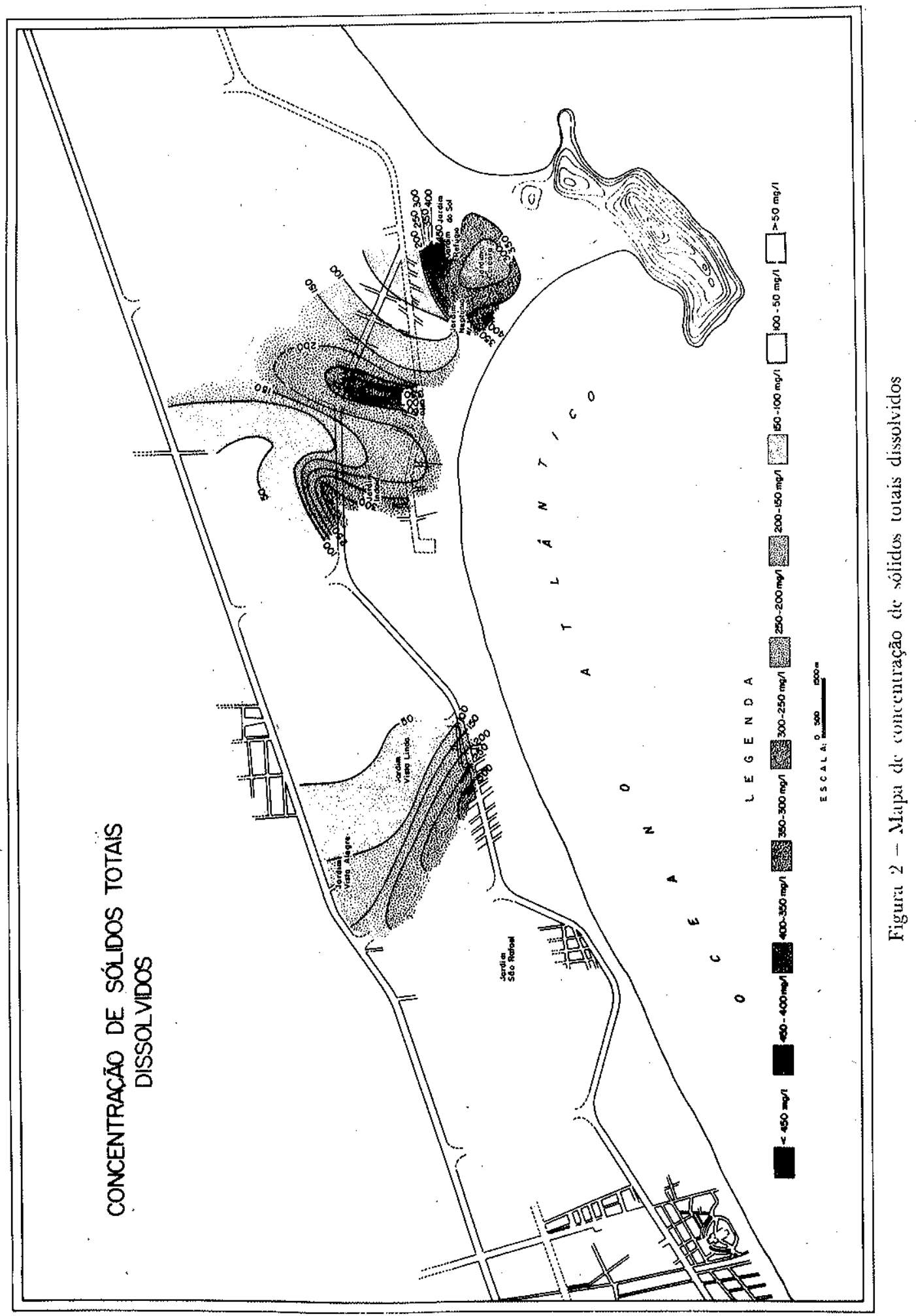



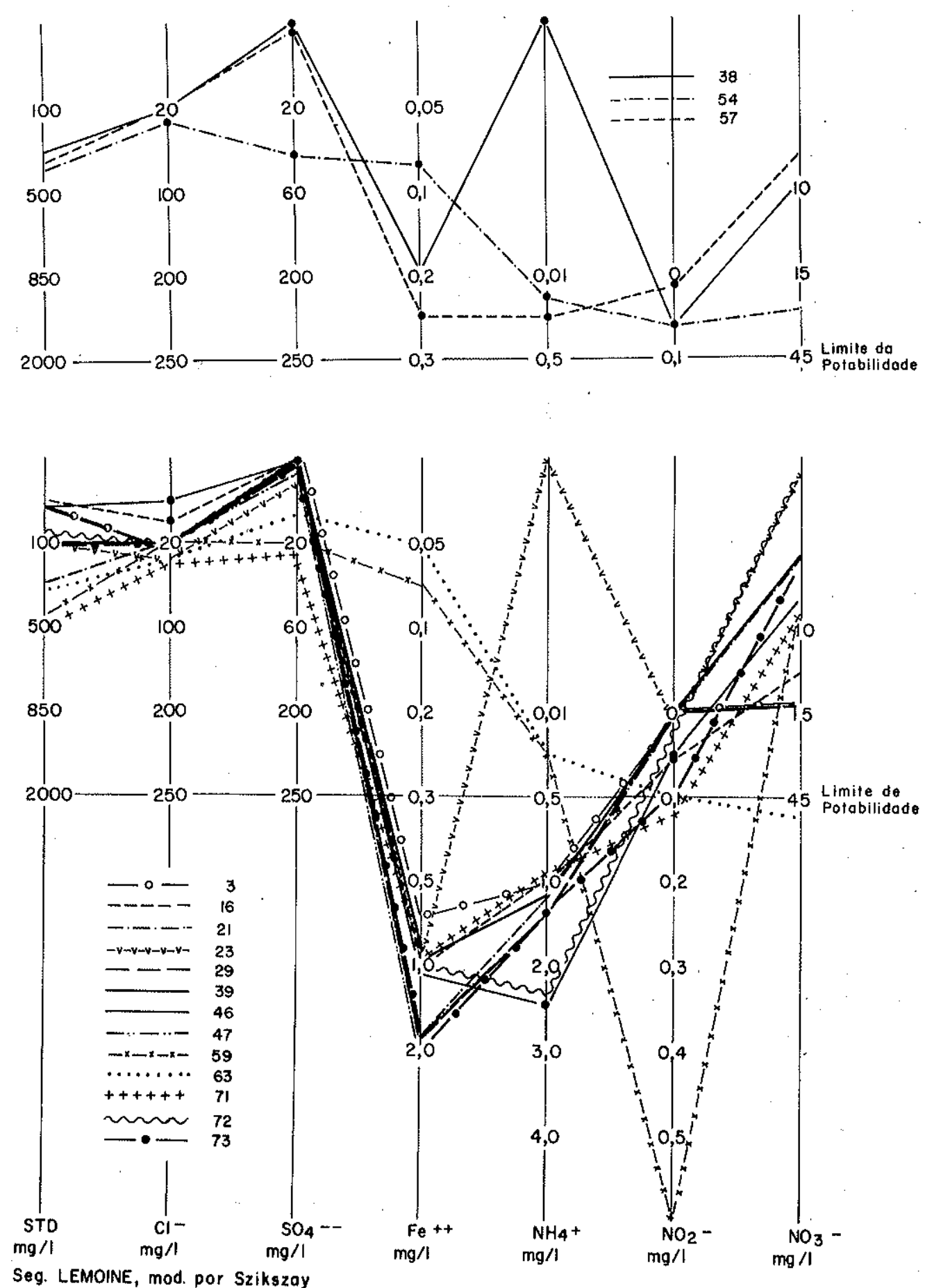

Figura 3 - Graus de potabilidade 
cesso de aeração. Instalações locais rudimentares já permitem obter btimos resultados através de um sistema de bandejas de aeração de reduzido tamanho.

Poços dotados de perímetro de proteção sanitária deverão propiciar água de qualidade higiênica compatível com as normas vigentes.

A utilização de fossas sépticas coletivas servirá para reduzir o número dos focos de poluição e restringir assim os riscos de deteriorização da qualidade das águas do manancial subterrâneo.

As especificações técnicas para as captações ressaltam a necessidade de se construir poços de grande diâmetro nos domínios dos paleovales, de preferência com drenos radiais, para se obter uma maior seção drenante e, conseqüentemente, grandes vazões com mínimo rebaixamento. Esta condição evitará igualmente a ascensão de água salgada que satura as partes mais profundas do pacote sedimentar.

Assim, a utilização de poço convenientemente protegido dos agentes sanitários de poluição e a adoção de técnicas de aeração e cloração podem transformar águas, naturalmente impróprias, em recursos de grande alcance social e econômico.

CONClUSöES Dos estudos geoquímicos conclui-se que:

-as águas podem ser classificadas em três grupos: clorossulfato calco-magnesianas, bicarbonato cálcicas e cloretadas e/ou bicarbonatadas sódicas;

- o estudo de troca de bases permitiu concluir que existe uma correlação entre a composição química das águas subterrâneas, as condições de circulação e a litologia, mormente o componente biodetrítico;

-a origem de ferro, amônia, nitrito e nitrato, como também gás carbônico e oxigênio, é devida à vegetação abundante; o cloreto é de influência marinha através dos aerossóis ou ascensão de água salgada que satura as partes profundas do pacote sedimentar;

- a variação de concentração de ferro e cloreto é controlada pela distância da praia; dos sólidos totais dissolvidos, amônia e nitratos são controlados pelas condições de drenagem; - do ponto de vista de uso doméstico, as águas, nas condições atuais de exploração, não são utilizáveis; no caso onde a região é mais densamente habitada, existem teores acima dos limites permitidos para uma água potável, em ferro, amônia e nitrito em certas regiões, devido à vegetação abundante e à presença de bactérias coliformes. Mas, se medidas corretivas e/ou preventivas forem adotadas, o manancial subterrâneo poderá alimentar um sistema de distribuição provisório.

Os estudos revelaram as possibilidades de exploração das águas subterrâneas para o abastecimento dos núcleos populacionais em desenvolvimento na área.

\section{BIBLIOGRAFIA}

BREMOND, R. e VUICHARD, R. - 1973 - Paramètres de la Qualité des Eaux, Minist. de la Protection de la Nature et de l'Environment, paris.

HEM, J. D. - 1959 - Study and interpretation of the chemical characteristics of natural water. Geol. Surv. Water Supply Paper 1473.

LEMOINE, B. - 1974 - Essai de Glassification et de Cartographie de la Qualite Chimique des Eaux Souterraines, B.R.G.M., 74 SGN 404 AME.

SCHOELLER, H. - 1962 - Les Eaux Souterraines. Masson \& Cie. Éditeurs, Paris. 